\title{
Роль электроэнергетики
}

\section{во внешнеэкономической экспансии КНР}

\author{
Раиса Алексеевна ЕПИХИНА \\ младший научный сотрудник \\ Московский государственный университет им. М.В. Ломоносова, 119991, \\ Ленинские горы, д. 1, стр. 46, Москва, Российская Федерация \\ E-mail: repikhina@econ.msu.ru \\ ORCID: 0000-0002-9787-2395
}

\section{ЦИТИРОВАНИЕ: Епихина Р.А. (2019) Роль электроэнергетики во внешнеэкономической экспансии КНР // Контуры глобальных трансформаций: политика, экономика, право. Т. 12. № 6. С. 188-202. \\ DOI: 10.23932/2542-0240-2019-12-6-9}

Статья поступила в редакцию 07.10.2019.

АННОТАЦИЯ. На проекты в сбере электроэнергетики приходится основной поток китайских зарубежных капиталовложений в инфраструктурные проекты в рамках инициативы «Один пояс, один путь» (ОПОП). В результате создаются предпосылки для долгосрочного доминирования Китая в одной из стратегччески важных отраслей в иелом ряде стран и регионов мира. В статье анализируется география, динамика и структура внешнеэкономической экспансии китайского капитала в зарубежную электроэнергетику. В частности, отмечается, что проекты осуществляются в основном государственными компаниями при содействии государственных финансовых институтов. Они реализуются главным образом в развивающихся странах в гидро- и угольной генерации. В 2010-е гг. китайские компании стали выходить и на рынки развитых стран, а также продвигать свои разработки в сбере альтернативной и атомной энергетики, в области передачи электроэнергии. Покупка активов в развитых странах позволяет Ки- таю перенимать передовые технологии и управленческие практики. В развиваюшихся странах КНР продвигает собственные технологии и стандарты (особенно в сбере передачи электроэнергии). При этом происходит постепенная институиионализация внешнеэкономической экспансии в электроэнергетике. В статье также показана взаимосвязь указанных прочессов с рядом внутренних проблем экономического развития в КНР. Так, в результате внешнеэкономической экспансии в электроэнергетике Китай осваивает существуюшие или создает новые рынки сбыта продукиии предприятий тяжелой промышленности, которые в условиях структурной трансбормации экономики КНР могли бы закрыться или значительно сократить масштабы выпуска. Это, в свою очередь, способствует поддержанию занятости. Тем не менее в последние годы китайские зарубежные капиталовложения в электроэнергетику и другие инфраструктурные и высокотехнологичные отрасли все чаще рассматриваются властями принимающих 
стран в контексте возможных угроз наииональной безопасности. Дальнейшее расширение присутствия китайского капитала в мировой электроэнергетике, по-видимому, будет все активнее сдерживаться.

КЛЮЧЕВЫЕ СЛОВА: КИтай, инвестиции, инновачии, ТНК, международное экономическое сотрудничество, электроэнергетика, уголь, сетевое хозяйство

На современном этапе для того, чтобы избежать попадания в ловушку среднего дохода, Китаю необходимо решить несколько задач. Во-первых, важно увеличивать вклад внутреннего потребления в рост ВВП. Во-вторых, нужно наращивать производство и поставки на внешние рынки высокотехнологичной продукции, прежде всего на базе китайских инноваций. Подобные меры призваны повысить загрузку производственных мощностей в КНР в условиях структурной трансформации экономики и торговой войны с США, а также сохранить рабочие места. Кроме того, они способствуют росту спроса на китайскую продукцию на внутреннем и внешнем рынках, расширению географии действия китайских технологических стандартов и формированию новых цепочек создания стоимости [Василенко, Чернядьев, Власов 2018; Игнатьев, Луконин 2018].

Важную роль в решении второй задачи играет внешнеэкономическая экспансия китайского капитала в целом и, в частности, в электроэнергетику - отрасль со значительным вкладом пере- довых технологий, в т. ч. разработанных в самом Китае. Причем, учитывая, что сроки эксплуатации генерирующих станций и линий электропередачи (ЛЭП) составляют несколько десятилетий, создаются предпосылки для долгосрочного доминирования Китая в одной из ключевых инфраструктурных отраслей в целом ряде стран и регионов мира.

\section{Основные политические драйверы внешнеэкономической экспансии в электроэнергетике}

Исторически электроэнергетика КНР была лишь в малой степени интегрирована в международно-экономические процессы ${ }^{1}$. На протяжении почти 40 лет (с 1960-х гг. до конца $\mathrm{XX}$ в.) китайские предприятия принимали участие в форме экономической помощи в международных проектах, главным образом строительства ГЭС. При этом ни о какой государственной стратегии транснационализации китайских компаний в условиях плановой экономики и на начальных этапах рыночных преобразований речи не шло. Проекты определялись и полностью финансировались правительством, а компании выступали лишь в качестве исполнителей ${ }^{2}$. В силу того, что инжиниринг, технологии строительства и качество оборудования китайского производства на тот момент были низкими, количество международных проектов было невелико. Географически такие проекты были сконцентрированы в беднейших стра-

\footnotetext{
1 Yang Q. (2017) China's Power Enterprises Open a New Chapter in the Implementation of the "Going Out" Strategy // Ying Da Wang, May 2017 // http://www.indaa.com.cn/zz/gjdwzz/gjdwzz201705/201705/P020170517353952429846.pdf, дата обращения 12.12.2019 (на китайском языке)

2 Liu Fengqiu (2014) The Rise of China's Hydropower Overseas // China Three Gorges Corporation, January 13, 2014 // http://www.ctg.com.cn/sxjt/sdbl/_303760/585222/index.html, дата обращения 12.12.2019 (на китайском языке).
} 
нах. ${ }^{3}$ Помимо этого Китай участвовал в трансграничных перетоках электричества ${ }^{4}$, а также поставлял на мировой рынок различные виды генерирующего и сетевого оборудования.

По мере развития национальной экономики китайские компании стали переходить к более сложным формам экономического взаимодействия, развивая инвестиционное сотрудничество. Этому способствовал ряд взаимно дополняющих реформ, инициатив и стратегий развития, принятых в начале первого десятилетия XXI в. и в 2010-х гг.

Так, в плане 10-й пятилетки (20012005 гг.) была закреплена обсуждавшаяся с конца 1990-х гг. идея «глобальной стратегии внешнеэкономического наступления» «Идти вовне», в рамках которой государство стало поощрять и поддерживать китайские предприятия, инвестирующие за рубеж. По мнению властей, только так можно было восполнить недостаток национальных природных ресурсов и рынка, развивать новые отрасли и масштабировать экспорт китайской продукции, а также постепенно формировать собственные ТНК, чтобы еще эффективнее конкурировать на мировом уровне [Гельбрас 2003, с. 85]. Впоследствии задачи развития международного сотрудничества ставились во всех пятилетних планах развития энергетики.

В 2002 г. в КНР была проведена реформа электроэнергетики, в результате которой вертикально-интегрированная монополия была разделена на пять генерирующих и две сетевые компании. В рамках реализации стратегии «Идти вовне» вновь образованные предприятия наряду с существовавшими на тот момент компаниями, специализирующимися в смежных областях (например, производстве оборудования для производства и передачи электроэнергии, добыче угля и проч.), стали участвовать в международных тендерах на поставку оборудования, а затем покупку активов и реализацию проектов за рубежом.

На внешнеэкономическую экспансию электроэнергетических компаний также повлияла инициатива «Один пояс - один путь» (ОПОП) - стратегия развития, предусматривающая масштабное строительство на территории стран-участниц объектов инфраструктуры, в т. ч. электроэнергетической. Кроме того, в 2015 г. власти КНР обнародовали план инновационного развития «Сделано в Китае - 2025», направленный на «ребрендинг» Китая и превращение его из производителя дешевых товаров широкого потребления не самого высокого качества в поставщика высококлассной промышленной продукции со значительной долей собственных технологических разработок. Впоследствии эти разработки должны были продвигаться на мировом рынке. В плане было выделено десять отраслей промышленности, в т. ч. производство электроэнергетического оборудования и продукции для «зеленой» энергетики, развитию которых должно было уделяться особое внимание.

\footnotetext{
3 Первым таким проектом стала ГЭС Цзинькан в Гвинее, которая строилась при участии КНР в 1963-1966 гг. См.: Yang Q. (2017) China's Power Enterprises Open a New Chapter in the Implementation of the "Going Out" Strategy // Ying Da Wang, May 2017 // http://www.indaa.com.cn/zz/gjdwzz/gjdwzz201705/201705/P020170517353952429846.pdf, дата обращения 12.12.2019 (на китайском языке).

4 По данным Государственного статистического управления КНР, Китай экспортирует и импортирует электрическую энергию с 1980-х гг. По состоянию на конец июля 2019 г., КНР осуществляла поставки электричества в Гонконг, Макао, Вьетнам, Монголию, Мьянму, КНДР и Лаос, а также импортировала его из России, Мьянмы, КНДР и Гонконга См.: 7-6 Electricity Balance Sheet (n/y) // National Bureau of Statistics of China // http://www.stats.gov.cn/yearbook/indexC.htm (на китайском языке); List of Importing Markets for a Product Exported by China, Product: 2716 Electrical energy (n/y) // ITC Trade Map // https://www.trademap. org/Country_SelProductCountry_TS.aspx?nvpm=1|156||||271600|||6|1|1|2|2|1|2|1|1, дата обращения 12.12.2019.
} 


\section{Трудности статистического} учета

Определить точные объемы зарубежных инвестиций КНР, в том числе в электроэнергетике, на основе официальной статистики достаточно трудно. Данные Министерства коммерции КНР, по общему мнению отечественных и иностранных ученых, некорректны, поскольку учитывают только капитал из КНР, в то время как в Китае и ряде стран-реципиентов распространена практика инвестирования через офшорные территории. Помимо этого, официальные данные главным образом опираются на сообщения компаний о собственных инвестициях, что часто приводит к тому, что в статистике Министерства коммерции КНР учитываются преимущественно крупные сделки, а мелкие могут опускаться [Игнатьев, Луконин 2018, с. 7; Кашин, Королев 2018, с. 80; Kong, Gallagher 2017, p. 837]. Кроме того, в официальной статистике сведения о зарубежных инвестициях в электроэнергетику приводятся в сумме с капиталовложениями в системы производства и снабжения теплом, газом и водой ${ }^{5}$. При этом не все компании предоставляют подробную информацию о зарубежных активах в своих годовых отчетах и на официальных сайтах. Информационные ресурсы о сделках по слиянию и поглощению с участием китайских компаний отражают лишь часть процесса транснационализации китайского бизнеса. Отдельно следует отметить, что в открытом доступе отсутствуют официальные данные о кредитном сотрудничестве между китайскими электроэнергетическими компаниями, банками и странамиреципиентами. Таким образом, в показателях, характеризующих структуру и объемы китайских зарубежных капиталовложений, возникают неизбежные искажения.

Приведем лишь некоторые оценки. Так, по подсчетам американских ученых, по состоянию на конец 2017 г. китайские национальные банки развития инвестировали в энергетику больше, чем крупнейшие западные международные банки развития, вместе взятые [Gallagher, Kamal, Jin, Chen, Ma 2018, p. 313]. Причем в 2000-2017 гг. в структуре всех китайских зарубежных финансов в энергетике лидировали вложения в генерацию электричества $(43,84 \%)^{6}$. С ними в целом согласны аналитики Mercator Institute for China Studies (Германия), осуществляющие мониторинг проектов в рамках ОПОП. По их данным, расходы на строительство электростанций и сетей занимают первое место в структуре вложений в инфраструктурные проекты, реализуемые китайскими компаниями в странах «Пояса и пути»?. Наконец, по сведениям Ассоциации электроэнергетических предприятий КНP (China Electricity Council), за первые 5 лет реализации инициативы (2013-2017 гг.) крупнейшие электроэнергетические предприятия страны подписали 494 контракта на общую сумму 91,2 млрд долл. ${ }^{8}$

\footnotetext{
52017 Statistical Bulletin of China's Outward Foreign Direct Investment (2018) // Ministry of Commerce of the People's Republic of China // http://images.mofcom.gov.cn/hzs/201810/20181029160118046.pdf, дата обращения 12.12.2019.

6 China's Global Energy Finance (n/y) // BU Global Development Policy Center // https://www.bu.edu/cgef/, дата обращения 12.12.2019.

7 Eder T.S., Mardell J. (2019) Powering the Belt and Road // MERICS, June 27, 2019 // https://www.merics.org/en/bri-tracker/ powering-the-belt-and-road, дата обращения 12.12.2019.

8 One Belt One Road Lights up the World - China Electricity Council Holds 2018 China Electricity Theme Day (2018) // China Electricity Council, July 26, 2018 // http://www.cec.org.cn/yaowenkuaidi/2018-07-26/183097.html, дата обращения 12.12.2019 (на китайском языке).
} 


\section{Китайские ТНК в сфере электроэнергетики}

За годы реализации стратегии «Идти вовне» и инициативы «Один пояс один путь» многие китайские электроэнергетические компании из предприятий, работающих преимущественно на внутреннем рынке, превратились в ТНК. Так, в 2017 г. в рейтинг 100 крупнейших нефинансовых ТНК КНР вошли более 10 электроэнергетических компаний, в частности, Государственная электросетевая корпорация Китая State Grid (ГЭК Китая), ряд крупных генерирующих предприятий, несколько компаний, специализирующихся на строительстве электростанций и поставках оборудования, в т. ч. для солнечной и ветроэнер- гетики, а также отдельные инвестиционные корпорации, имеющие активы, в числе прочих, и в электроэнергетике $\mathrm{e}^{9}$ (табл. 1).

Их включение в международно-экономические отношения на современном этапе происходит, главным образом, в четырех формах:

- международная помощь развитию;

- экспорт оборудования;

- строительство объектов электроэнергетики за рубежом по контракту (ЕРC);

- прямые и портфельные инвестиции (в т. ч. покупка доли в иностранной компании и вложения, предусматривающие строительство объектов за рубежом «с нуля» (greenfield-инвестиции)).

\section{Таблица 1. Ведущие китайские ТНК в сфере электроэнергетики}

Table 1. Leading Chinese TNCs in the electricity sector

\begin{tabular}{|c|c|c|c|c|c|c|c|c|}
\hline \multirow{2}{*}{$\begin{array}{l}\text { Название компании } \\
\text { и место в рейтинге } \\
\text { в } 2017 \text { г. }\end{array}$} & \multicolumn{2}{|c|}{$\begin{array}{c}\text { Зарубежные } \\
\text { активы, } \\
\text { млрд юаней }\end{array}$} & \multicolumn{2}{|c|}{$\begin{array}{c}\text { Зарубежные } \\
\text { продажи, млрд } \\
\text { юаней }\end{array}$} & \multicolumn{2}{|c|}{$\begin{array}{l}\text { Зарубежный } \\
\text { персонал, } \\
\text { человек }\end{array}$} & \multicolumn{2}{|c|}{ Ит, \% } \\
\hline & 2011 r. & 2017 r. & 2011 r. & 2017 r. & 2011 r. & 2017 r. & 2011 r. & 2017 r. \\
\hline 9. State Grid & 25,11 & 289,33 & 2,54 & 103,81 & 1011 & 15620 & 0,45 & 4,53 \\
\hline 19. Power China & 56,43 & 118,30 & 51,51 & 89,03 & 2128 & 94326 & 17,5 & 30,8 \\
\hline 32. China Huaneng Group & 47,9 & 59,06 & 22,19 & 11,74 & 1070 & 1625 & 5,14 & 3,79 \\
\hline 76. Trina Solar ${ }^{10}$ & - & 13,23 & - & 13,82 & - & 2042 & - & 34,37 \\
\hline 80. Goldwind & - & 11,86 & - & 2,73 & - & 223 & - & 9,94 \\
\hline
\end{tabular}

* ИТ - индекс транснациональности, который вычисляется как среднеарифметическое доли зарубежных активов в общем объеме активов, доли зарубежных продаж в общей стоимости продаж и доли зарубежного персонала в численности всего персонала данной ТНК [Лучко 2017, с. 49].

Составлено автором по: Тор 100 Chinese Multinational Corporations and Their Internationalization Indices-2012 (n/y) // China Enterprise Confederation / China Enterprise Directors Association // http://www.cec-ceda.org.cn/huodong/2013china500/001 kuag uozhishu-2012.htm, дата обращения 30.03.2019 (на китайском языке); Notice on the Publication of Top 100 Chinese Multinational Corporations and Their Internationalization Indices-2018 (2018) // China Enterprise Confederation / China Enterprise Directors Association, August 20, 2018 // http://www.cec-ceda.org.cn/download/37791_1_1536027366.doсх, дата обращения 30.03.2019 (на китайском языке).

9 Yang Q. (2017) China's Power Enterprises Open a New Chapter in the Implementation of the "Going Out" Strategy // Ying Da Wang, May 2017 // http://www.indaa.com.cn/zz/gjdwzz/gjdwzz201705/201705/Р020170517353952429846.pdf, дата обращения 12.12.2019 (на китайском языке).

10 Поставщики солнечных батарей Trina Solar и Jinko Solar были включены в рейтинг только с 2016 г., а производитель ветрогенераторов Goldwind - только в 2017 г. 
В числе крупных репутационных проектов можно выделить, например, покупку корпорацией State Grid (SGCC, ГЭК Китая) сетевых активов в Бразилии и последующее строительство там ЛЭП сверхвысокого напряжения по передовым китайским разработкам, а также 33,5-процентное участие China General Nuclear Power Group (CGN) в АЭС Hinkley Point C в Великобритании ${ }^{11}$.

Как показано в табл. 1, за сравнительно короткий период предприятия отрасли существенно увеличили свои зарубежные активы, в целом повысили доходы от зарубежных продаж и количество сотрудников, занятых на проектах за границей, что способствовало росту индекса их транснациональности. При этом у State Grid (ГЭК Китая) и генерирующей компании China Huaneng Group этот показатель остался на порядок меньше, чем у инжиниринговой компании Power China и поставщиков оборудования, таких как Trina Solar и Goldwind. Это обстоятельство, по-видимому, обусловлено наличием у генерирующих и сетевых компаний крупных активов в самом Китае (т. е. большим знаменателем в формуле, по которой рассчитывается индекс транснациональности) и рассмотренными выше историческими особенностями их развития.
Основные особенности и тенденции

внешнеэкономической экспансии КНР в сфере электроэнергетики

Доминирующая роль государственного сектора. В электроэнергетике и ряде смежных отраслей в Китае превалируют государственные предприятия. Власти поддерживают их транснационализацию с целью формирования из их числа «национальных чемпионов». ${ }^{12}$ В связи с этим неудивительно, что китайские зарубежные проекты в электроэнергетике осуществляются главным образом государственными компаниями ${ }^{13}-$ инжиниринговыми, крупными генерирующими и сетевыми, а также некоторыми региональными энергетическими предприятиями и отраслевыми группами.

В то же время значительную поддержку в продвижении на зарубежных рынках им оказывают государственные политические и коммерческие банки, а также различные фонды, финансируемые КНР.

Преобладание государства в электроэнергетике и финансовом секторе $\mathrm{e}^{14}$ существенно упрощает координацию между участниками китайских зарубежных проектов [Kong, Gallagher 2017, pp. 834-835]. Для сравнения: в миро-

11 Hinkley Point C Hits Its Biggest Milestone yet (2019) // EDF Energy, June 28, 2019 // https://www.edfenergy.com/media-centre/ news-releases/hinkley-point-c-hits-its-biggest-milestone-yet, дата обращения 12.12.2019.

12 Zhu L. (2018) SOEs' Internationalization Process Will Be Accelerated // China Daily, February 13, 2018 // http://www.chinadaily. com.cn/a/201802/13/WS5a827d0ba3106e7dcc13c812.html, дата обращения 12.12.2019.

13 Негосударственные компании (инвесторы, подрядчики и поставщики оборудования) в основном представлены в проектах в сфере альтернативной генерации [Nicholas 2018; Cabré, Gallagher, Li 2018, p. 43].

14 Вместе с тем, несмотря на ведущую роль государства и задачи по реализации политических инициатив, до реализации главным образом доходят проекты, которые находятся на пересечении стратегических задач властей КНР, коммерческих интересов компаний и объективной необходимости стран-реципиентов в электрической энергии. В противном случае их отменяют даже в странах - стратегических партнерах. Так, по результатам технико-экономического обоснования китайской стороной были отменены некоторые проекты на территории РФ. В частности, в октябре 2017 г. компания Shenhua отказалась от проекта в Амурской области, когда выяснилось, что он не окупится. Инвестиции оценивались в 8-10 млрд долл. См.: Джумайло А. (2018) «Ростех» выбирается из угля // Коммерсант. 29 марта 2018 // https://www.kommersant.ru/doc/3586925, дата обращения 12.12.2019 
вой практике дорогостоящие проекты в энергетике часто финансируются консорциумами, состоящими из нескольких десятков компаний разных форм собственности, что существенно осложняет процесс согласования [Cabré, Gallagher, Li 2018, p. 46].

К настоящему времени в научной и экспертной среде сложилось единое мнение $^{15}$, что кредиты государственных политических банков КНР (China Development Bank и China Eximbank) ${ }^{16}$ играют важнейшую роль в реализации китайской внешнеэкономической экспансии, в т. ч. в сфере электроэнерге- тики. Во многом благодаря им Китай окончательно утвердился в статусе ведущего источника капитала в проекты развития в энергетике.

Преобладание в структуре зарубежных капиталовложений в электроэнергетике традиционных видов генерации преимущественно в развивающихся странах. Китайские компании начинали свой путь вовне с освоения рынков развивающихся стран Азии и Африки, где они в основном осуществляли строительство объектов традиционной генерации [Dan, Qiu, Lin

\section{Рисунок 1. Структура китайских зарубежных инвестиций в генерацию электроэнергии в 2000-2017 гг., \% \\ Fig. 1. Structure of Chinese foreign investment in generation electricity generation in $2000-2017, \%$}

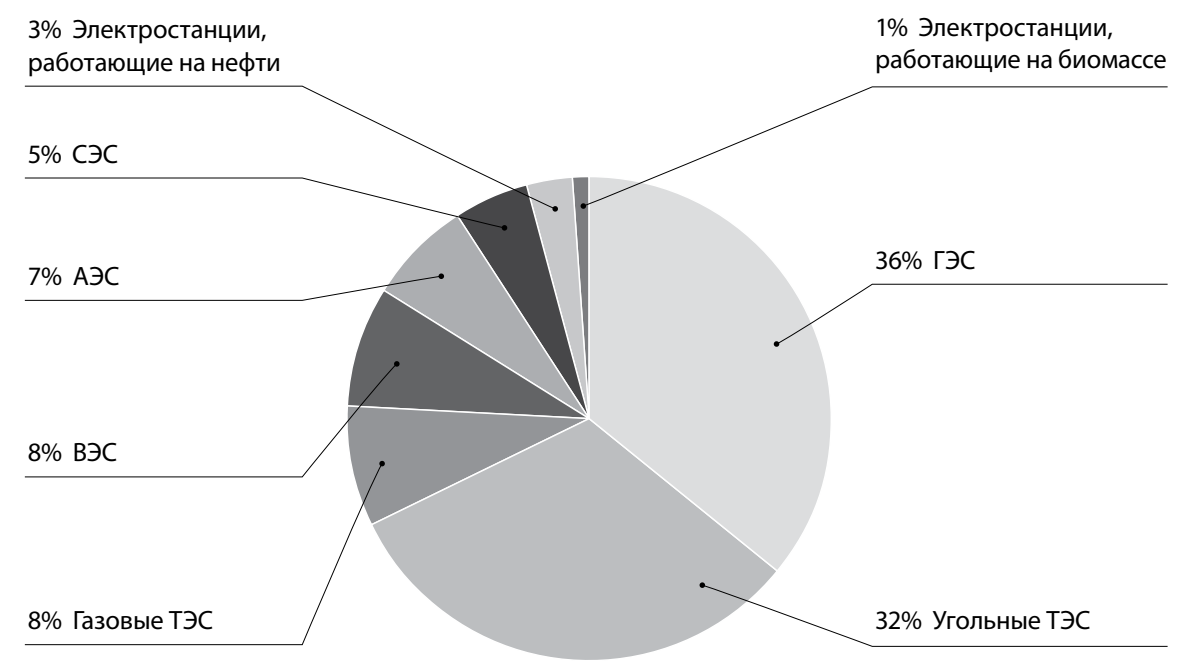

* ВЭС - ветроэлектростанции, СЭС - солнечные электростанции.

Составлено автором по: [Cabré, Gallagher, Li 2018, p. 42].

15 Подробнее см.: [Kong, Gallagher 2016, pp. 19-20; Гемуева 2018, с. 58-60]; Outlook of Belt and Road International Power Cooperation in 2018 (2018) // Deloitte // https://www2.deloitte.com/content/dam/Deloitte/cn/Documents/energy-resources/ deloitte-cn-er-outlook-of-belt-and-road-international-power-cooperation-in-2018-en-180508.pdf, дата обращения 12.12.2019.

16 Банки КНР также выдают кредиты иностранным правительствам и компаниям для реализации проектов в сфере электроэнергетики без участия китайского бизнеса, однако количество таких кредитных линий невелико. Так, по оценкам Global Environmental Institute, в 2001-2016 гг. китайские банки выдали займы на реализацию 234 проектов строительства угольных электростанций в рамках ОПОП. Из них только 9 не предусматривали участия китайских компаний [Ren, Liu, Zhang 2017$].$ 
2018]. ГЭС ${ }^{17}$ и угольные ТЭС до сих пор доминируют в структуре китайских зарубежных капиталовложений (рис. 1). КНР является основным источником капитала в угольной генерации на мировом рынке [Shearer, Mathew-Shah, Myllyvirta, Yu, Nace 2018]. Из 120 крупнейших компаний, занимающихся строительством угольных ТЭС, 25 из Китая (в т. ч. 2 - из Гонконга) ${ }^{18}$. По оценкам экспертов, как минимум 16\% всех угольных ТЭС за пределами Китая строятся, финансируются или принадлежат китайским компаниям [Shearer, Mathew-Shah, Myllyvirta, Yu, Nace 2018]. Крупнейшими получателями капитала из КНР в этом сегменте являются Индия, Индонезия, Монголия, Вьетнам, Турция.

Концентрация китайского капитала в традиционных секторах генерации в развивающихся странах обусловлена несколькими факторами.

Во-первых, в развивающихся странах сохраняются трудности с удовлетворением растущего спроса на электричество, например, в Индии, Иране, Пакистане, странах Центральной Азии ${ }^{19}$, а действующие стандарты экологической безопасности существенно ниже, чем в развитых странах. Некоторые из стран-реципиентов имеют собственные месторождения угля или богатый гидропотенциал.

Во-вторых, китайские компании обладают опытом строительства объек- тов традиционной генерации и возможностями привлечения финансовых ресурсов. Последнее особенно важно, учитывая, что по состоянию на февраль 2019 г. 20 банков прекратили финансирование новых проектов в области угольной генерации. В их числе Societe Generale, BNP Paribas, Deutsche Bank, Standard Chartered, Barclays ${ }^{20}$. В то же время международные финансовые институты крайне неохотно идут на сотрудничество со странами с высокими рисками, многие из которых расположены в странах Азии и Африки [Гемуева 2018, с. 70].

В-третьих, внешний рынок создает новые возможности для китайских компаний в сфере традиционной генерации в условиях замедления темпов роста ВВП и структурных трансформаций в экономике КНР. Так, в 2019 г. вице-президент компании China Three Gorges заявил, что в связи с ростом издержек строительства в КНР в целом и сокращением возможностей для строительства новых ГЭС в Китае, в частности, компания сконцентрируется исключительно на зарубежных рынках, а именно на странах Южной и ЮгоВосточной Азии, Африки и Латинской Америки ${ }^{21}$.

В-четвертых, за счет строительства угольных ТЭС за рубежом, в т. ч. в странах, где доля этого вида топлива в производстве электричества невелика или равна нулю (например, Египет и

\footnotetext{
17 По состоянию на начало 2019 г. китайские компании построили в 140 странах мира более 300 ГЭС суммарной установленной мощностью 81 ГВт. См.: Chinese Enterprises Represent 70 Percent of Global Hydropower Market (2019) // People's Daily Online, January 22, 2019 // http://en.people.cn/n3/2019/0122/c90000-9540389.html?platform=hootsuite, дата обращения 12.12.2019.

18 Global Coal Exit List (n/y) // Urgewald // https://coalexit.org/database, дата обращения 12.12.2019.

19 Report on Development of China's Outward Investment 2018 (2018) // Ministry of Commerce of the People's Republic of China // http://images.mofcom.gov.cn/fec/201901/20190128155348158.pdf, дата обращения 12.12.2019.

20 List of Banks Which Have Ended Direct Finance for New Coal Mines/Plants (n/y) // Banktrack // https://www.banktrack.org/page/ list_of_banks_which_have_ended_direct_finance_for_new_coal_minesplants, дата обращения 12.12.2019; Harper J. (2019) Banks around the World Opt to Offload Coal // Deutsche Welle, February 27, 2019 // https://www.dw.com/en/banks-around-the-worldopt-to-offload-coal/a-47708877, дата обращения 12.12.2019.

21 Xu M., Stanway D. (2019) China's Three Gorges Rules out New Domestic Hydro Projects // Reuters, January 9, 2019 // https://www.reuters.com/article/china-hydropower-threegorges-idUSL3N1Z91QN, дата обращения 12.12.2019.
} 
Пакистан), Китай создает потенциальные рынки для его сбыта в будущем ${ }^{22}$. Темпы роста потребления угля в КНР постепенно сокращаются в результате замедления темпов роста ВВП и снижения удельного веса вторичного сектора в его структуре, а также в ответ на экологическую политику. Кроме того, этому способствует закрытие избыточных генерирующих мощностей в теплоэнергетике страны в рамках структурной реформы предложения. При этом власти пытаются избежать масштабного сокращения рабочих. В связи с этим для КНР важно найти альтернативные формы применения топлива и новые возможности сбыта за рубежом.

Вместе с тем, поскольку эксплуатация крупных ГЭС и угольных ТЭС сопряжена с серьезными экологическими рисками, масштабная реализация китайскими компаниями подобных проектов за рубежом подрывает имидж КНР как нового мирового лидера экологической повестки ${ }^{23}$.

Постепенная диверсификация зарубежных капиталовложений за счет возобновляемых источников энергии (ВИЭ). В 2010-е гг. Китай, с одной стороны, продолжал укреплять свои позиции в традиционных секторах, а с другой, участвовал в проектах развития ВИЭ и сетевой инфраструктуры. Рост инвестиций в альтернативную энергетику в эти годы во многом связан с повышением внимания к проблеме глобального потепления и загрязнения окружающей среды. Кроме того, за счет возможности апробации технологий на емком китайском рынке и более дешевого по сравнению с продукцией из развитых стран производства себестоимость ВИЭ в КНР последовательно снижалась. Этот процесс обуславливал рост конкурентоспособности данных проектов на зарубежных рынках.

Инвестиции в ВИЭ позволили китайским компаниям диверсифицировать сбыт своей продукции за рубежом в условиях перегретого внутреннего рынка, а также перенять отдельные передовые технологии, в частности, в офшорной ветрогенерации. Их также привлекали более низкие, по сравнению с угольной генерацией, операционные и инвестиционные риски ветроэнергетики в развитых странах и преимущества, предоставляемые в рамках регуляторного режима, стимулирующего развитие чистой энергетики (например, сниженные налоги или повышенные тарифы на энергию ВИЭ) [Nicholas 2018]. Наконец, альтернативная энергетика в большинстве развивающихся стран - это сравнительно новый сектор в экономике, в котором для китайских инвесторов открываются возможности вложений в рынки с меньшим суверенным риском ${ }^{24}$, нежели в сфере добычи углеводородов [Cabré, Gallagher, Li 2018, pp. 46-47].

Развитие инвестиционных проектов в высокотехнологичных секторах электроэнергетики (сети, АЭС). Китайские проекты в области сетевой инфраструктуры в значительной степени направлены на продвижение на мировом уровне собственных технологий и стандартов smart grid и ЛЭП сверхвысокого напряжения для передачи энер-

\footnotetext{
22 Saha S., Lou T. (2017) China's Coal Problem. How It Undermines the Fight against Climate Change // Foreign Affairs, August 4, 2017 // https://www.foreignaffairs.com/articles/china/2017-08-04/chinas-coal-problem, дата обращения 12.12.2019.

23 Economy E. (2017) Why China Is no Climate Leader // Politico Magazine, June 12, 2017 // https://www.politico.com/magazine/ story/2017/06/12/why-china-is-no-climate-leader-215249, дата обращения 12.12.2019.

24 Chang Y. (2018) China Resources Power Will Actively Participate in the Global Offshore Wind Development // Zhongguo nengyuan bao, August 13, 2018 // http://paper.people.com.cn/zgnyb/html/2018-08/13/content_1874855.htm, дата обращения 12.12 .2019 (на китайском языке).
} 
гии на большие расстояния. Китай является единственной страной, которая масштабно и достаточно быстро внедряет инновации в этой сфере ${ }^{25}$. Таким образом, в этом сравнительно молодом и высокотехнологичном сегменте рынка у КНР есть возможность перехватить лидерство и установить наиболее выгодные для себя условия на годы вперед. Недавнее избрание бывшего главы ГЭК Китая Шу Иньбяо на должность председателя Международной электротехнической комиссии (International Electrotechnical Commission, IEC) на период с 2020 по 2022 г. позволит ему активнее продвигать китайские техстандарты электрических сетей на мировом уровне ${ }^{26}$.

Схожие цели по формированию у КНР имиджа технологического лидера стоят и перед компаниями в сфере атомной энергетики. Помимо упомянутой выше АЭС Hinkley Point C в Beликобритании, Китай уже осуществил строительство АЭС в Пакистане и в настоящее время ведет переговоры с Аргентиной, Румынией и Турцией. Причем в рамках многих проектов планируется установка адаптированных на базе зарубежных технологий китайских реакторов ${ }^{27}$.

Расширение географии зарубежных капиталовложений в электроэнергетике и освоение рынков разви- тых стран ${ }^{28}$. Несмотря на то, что в развитых странах коэффициент возврата инвестиций ниже, чем в развивающихся, новые проекты в сочетании с уже имеющимися активами позволили китайским компаниям повысить надежность и устойчивость своих инвестиционных портфелей. Помимо этого, наличие мощностей в странах, в которых уже проведена реформа электроэнергетики, позволяет накопить опыт управления в альтернативных условиях и подготовиться к трансформации регулирования отрасли, которая происходит и в Китае [Dan, Qiu, Lin 2018]. Выход на рынки развитых стран также способствует модернизации предприятий отрасли. Наконец, после мирового финансового кризиса 2008 г. многие развитые страны испытывали трудности с финансированием или необходимость продажи части активов. Именно на этот период пришелся масштабный рост китайских инвестиций в целом и в зарубежные электроэнергетические проекты в частности ${ }^{29}$.

Институционализация внешнеэкономической экспансии в электроэнергетике. В 2015 г. на саммите $\mathrm{OOH}$ по устойчивому развитию Си Цзиньпин выдвинул инициативу по созданию глобальной энергетической сети ${ }^{30}$. Год спустя для решения поставленной задачи была создана Организация

\footnotetext{
25 Power Play: China's UHV Technology and Global Standard (2015) // Paulson Institute. Paulson Papers on Standards, April 2015 // http://www.paulsoninstitute.org/wp-content/uploads/2017/01/PPS_UHV_English_R.pdf, дата обращения 12.12.2019. 26 For the First Time in 112 Years! Chairman of State Grid Corporation of China Elected as Chairman of the International Electrotechnical Commission (2018) // The Paper, October 26, 2018 // https://www.thepaper.cn/newsDetail_forward_2567221, дата обращения 12.12.2019 (на китайском языке).

27 Nuclear Power in China (2019) // World Nuclear Association, October 2019 // https://www.world-nuclear.org/information-library/ country-profiles/countries-a-f/china-nuclear-power.aspx, дата обращения 12.12.2019.

28 Формы реализации инвестиционных проектов в развивающихся и развитых странах различаются [Dan, Qiu, Lin 2018]. Если на развивающихся рынках они в основном предлагают готовые инжиниринговые решения, предполагающие строительство объектов генерации и сетевой инфраструктуры «с нуля», то в развитых странах китайские компании чаще покупают доли в компаниях путем слияний и поглощений.

29 China Global Investment Tracker (n/y) // American Enterprise Institute // http://www.aei.org/china-global-investment-tracker/, дата обращения 12.12.2019.

30 Six Agreements Signed and Plan for Belt and Road Energy Interconnection Released (n/y) // Global Energy Interconnection Development and Cooperation Organization // https://m.geidco.org/article/633, дата обращения 12.12.2019.
} 
по развитию и сотрудничеству в области глобального объединения энергосистем (Global Energy Interconnection Development and Cooperation Organization, GEIDCO). Она является международной некоммерческой организацией и активно сотрудничает с исследовательскими центрами, отдельными компаниями, региональными и международными организациями, такими как Лига арабских государств, Африканский союз и ООН [Mazzucchi 2018]. Кроме того, GEIDCO считается важнейшим элементом Энергетического шелкового пути. Главной целью, которую ставят авторы проекта, является развитие ВИЭ. Учитывая, что их широкое внедрение неразрывно связано с модернизацией сетевого хозяйства, такой подход представляется вполне обоснованным. Предполагается, что к 2050 г. члены GEIDCO построят 17 баз гидрогенерации, 19 баз ветрогенерации и 13 баз производства солнечной энергии, а также интегрируют их в глобальную сеть, состоящую из 5 горизонтальных и 6 вертикальных магистральных сетей, объединяющих Европу, Азию и Африку ${ }^{31}$.

Вместе с тем деятельность GEIDCO во многом направлена на поддержку интернационализации китайских электроэнергетических компаний, прежде всего State Grid. Главным идеологом и главой НКО является бывший председатель совета директоров State Grid Лю Чжэнья, и именно эта компания является учредителем Организации ${ }^{32}$. $\mathrm{He}$ смотря на увеличение количества ее зарубежных членов, более половины участников по-прежнему зарегистрированы в КНР. В их числе - ведущие электроэнергетические ТНК страны и их дочерние структуры ${ }^{33}$.

Таким образом, GEIDCO является одновременно и репутационным проектом, направленным на формирование образа КНР как мирового лидера в развитии передовых технологий производства и передачи электричества, и зонтичной программой, в рамках которой Китай продвигает свои технологические разработки на внешних рынках и поддерживает двух- и многосторонние проекты китайских электроэнергетических компаний.

Выход китайских электроэнергетических предприятий на внешние рынки играет важную роль во внешнеэкономической экспансии КНР и оказывает значительное влияние на мировую энергетику. Китайские компании не только продают оборудование для электростанций, но и покупают доли в компаниях, а также строят объекты «с нуля». Они представлены во всех звеньях производственной цепочки практически во всех видах традиционной и возобновляемой генерации и передачи электроэнергии на рынках как развивающихся, так и развитых стран.

Зарубежные инвестиции в электроэнергетику часто реализуются по схожей модели, ключевую роль в которой играет госсектор. Государственные банки и фонды КНР финансируют проекты китайских (в основном также государственных) компаний за рубе-

31 Development Report on Global Energy Interconnection for Promoting the Belt and Road (2019) // Global Energy Interconnection Development and Cooperation Organization, April 2019 // https://img1.nengapp.com/tech/ydyl/fzbg_en.html, дата обращения 12.12.2019.

32 State Grid Corporate Social Responsibility Report 2016 (2017) // State Grid Corporation of China, February 2017 // http://www.sgcc.com.cn/html/files/2018-07/28/20180728130448830583544.pdf, дата обращения 12.12.2019.

33 List of Members (n/y) // Global Energy Interconnection Development and Cooperation Organization // https://www.geidco.org/ members/list/, дата обращения 12.12.2019 (на китайском языке). 
жом. Финансовые ресурсы часто предоставляются для покупки оборудования в КНР и сооружения объектов при участии китайских строителей.

При этом внешнеэкономическая экспансия во многом используется для решения внутренних проблем развития экономики КНР.

Во-первых, поставки оборудования и инвестиции, предусматривающие строительство "с нуля», позволяют осваивать или создавать новые рынки сбыта генерирующего и сетевого оборудования. За счет этого появляется возможность поддерживать занятость и загрузку предприятий тяжелой промышленности, которые в условиях структурной трансформации экономики КНР могли бы закрыться или значительно сократить масштабы выпуска. Кроме того, такие капиталовложения также направлены на продвижение за рубежом собственных разработок и технологических стандартов. При этом КНР стремится занять лидирующие позиции в передовых наукоемких секторах в отрасли, таких как интеллектуальные сети, ВИЭ, хранение электроэнергии, а также целом ряде смежных отраслей.

Во-вторых, многочисленные проекты в развивающихся странах не только способствуют решению в них проблемы дефицита энергоснабжения и повышения качества жизни, но и позволяют заложить основу для развития в будущем любых энергоемких отраслей промышленности, в т. ч. при участии китайского капитала. За счет этого у КНР появляются новые возможности для формирования альтернативных цепочек создания стоимости и переноса собственных предприятий ${ }^{34}$.

В-третьих, за счет покупки активов на развитых рынках компании осваивают самые современные технологии и стандарты, а также перенимают практики управления электроэнергетическими предприятиями в рамках рынка.

Тем не менее дальнейшее расширение присутствия китайского капитала в мировой электроэнергетике, повидимому, будет все активнее сдерживаться. Этому будет способствовать усиление контроля китайских властей за оттоком капитала и актуализация экологической повестки в развивающихся странах. Кроме того, в последние годы китайские зарубежные капиталовложения в электроэнергетику и другие инфраструктурные и высокотехнологичные отрасли все чаще рассматриваются властями принимающих стран в контексте потенциальных угроз национальной безопасности. В связи с этим сделки с участием китайского капитала подвергаются дополнительным проверкам или отменяются. Так, в 2016 г. под предлогом угроз национальной безопасности правительство Австралии отменило сделку по продаже сетевой компании Ausgrid китайской State Grid. ${ }^{35}$ В 2018 г. немецкий государственный банк KfW выкупил 20\%-ю долю в компании $50 \mathrm{Hertz}$ Transmission $\mathrm{GmbH}$, чтобы предотвратить попытку ее приобретения китайским инвестором. ${ }^{36}$ Вместе с тем можно ожидать роста конкуренции со сторо-

\footnotetext{
34 Eder T.S., Mardell J. (2019) Powering the Belt and Road // MERICS, June 27, 2019 // https://www.merics.org/en/bri-tracker/powering-the-belt-and-road, дата обращения 12.12.2019.

35 Williams P., Foley B. (2016) Australia Discovers Cost of Blocking China in Ausgrid Sale //The Sydney Morning Herald, October 21, 2016 // https://www.smh.com.au/business/australia-discovers-cost-of-blocking-china-in-ausgrid-sale-20161021-gs7dbt.html, дата обращения 12.12.2019.

36 Bryan V., Heller G. (2018) Germany Moves to Protect Key Companies from Chinese Investors // Reuters, July 27, 2018 // https://uk.reuters.com/article/us-50hertz-m-a-kfw/germany-moves-to-protect-key-companies-from-chinese-investors-idUKKBN1KHORB, дата обращения 12.12.2019.
} 
ны некитайских электроэнергетических компаний. В связи с этим открытым остается вопрос о том, удастся ли Китаю компенсировать недостатки старой модели экономического развития, сдерживающие его переход к интенсивному росту на основе инноваций, за счет внешнего рынка.

\section{Список литературы}

Василенко А.С., Чернядьев Д.Н., Власов С.А. (2018) Структурная трансформация экономики Китая: успех или неудача? // Вопросы экономики. № 7. С. 6581. DOI: 10.32609/0042-8736-2018-7-65-81

Гельбрас В.Г. (2003) Китай: возрождение национальной идеи // Полития. № 2. С. 80-90. DOI: 10.30570/2078-5089-2003-29-2-80-90

Гемуева К.А. (2018) Китайские инфраструктурные проекты в странах Африки южнее Сахары: кредитное финансирование // Контуры глобальных трансформаций: политика, экономика, право. Т. 11. № 5. С. 55-73. DOI: 10.23932/2542-0240-2018-11-5-55-73

Игнатьев С., Луконин С. (2018) Инвестиционные связи Китая со странами Африки // Мировая экономика и международные отношения. Т. 62. № 10. С. 5-12. DOI: 10.20542/0131-2227-2018-62-10-5-12

Кашин В., Королев А. (2018) Помощь КНР странам Центральной Азии // Мировая экономика и международные отношения. Т. 62. № 3. С. 78-85. DOI: 10.20542/0131-2227-2018-62-3-78-85

Лучко М. (2017) Китайские ТНК на мировом инвестиционном поле // Мировая экономика и международные отношения. Т. 61. № 9. С. 45-53. DOI: 10.20542/0131-2227-2017-61-9-45-53

Cabré M.M., Gallagher K.P., Li Z. (2018) Renewable Energy: The Trillion Dollar Opportunity for Chinese Overseas Investment // China \& World Economy, vol. 26, no 6, pp. 27-49. DOI: $10.1111 /$ cwe. 12260
Dan X., Qiu Z., Lin J. (2018) Overseas Investment Opportunities in the Power Sector. China's Electricity Industry Transformation Series // PwC, January 15, 2018 // https://www.strategyand.pwc.com/media/ file/PU-series-Overseas-investment-opportunities-in-the-power-sector_CN.pdf, дата обращения 12.12.2019 (на китайском языке).

Gallagher K.P., Kamal R., Jin J., Chen Y., Ma X. (2018) Energizing Development Finance? The Benefits and Risks of China's Development Finance in the Global Energy Sector // Energy Policy, vol. 122, pp. 313321. DOI: 10.1016/j.enpol.2018.06.009

Kong B., Galagher K.P. (2016) The Globalization of Chinese Energy Companies: The Role of State Finance // Boston University, June 2016 // https://www.bu.edu/ pardeeschool/files/2016/06/Globalization. Final_.pdf, дата обращения 12.12.2019.

Kong B., Gallagher K.P. (2017) Globalizing Chinese Energy Finance: The Role of Policy Banks // Journal of Contemporary China, vol. 26, no 108, pp. 834-851. DOI: 10.1080/10670564.2017.1337307

Mazzucchi N. (2018) China and European Electricity Networks: Strategy and Issues // Fondation pour la Recherche Stratégique. Note №17/2018, September 12, 2018 // https://www.frstrategie.org/sites/ default/files/documents/publications/ notes/2018/201817.pdf, дата обращения 12.12.2019.

Nicholas S. (2018) China Is Investing Heavily in European Wind. Asian Superpower's Renewable Energy Ambitions Go beyond Its Belt and Road Footprint // Institute for Energy Economics and Financial Analysis, August 2018 // http://ieefa. org/wp-content/uploads/2018/08/China_ Research_Brief_August-2018.pdf, дата обращения 12.12.2019.

Ren P., Liu C., Zhang L. (2017) China's Involvement in Coal-fired Power Projects along the Belt and Road // Global Environmental Institute, May 2017 // http://www.geichina.org/_upload/file/re- 
port/China\%27s_Involvement_in_Coalfired_Power_Projects_OBOR_EN.pdf, дата обращения 12.12.2019.

Shearer C., Mathew-Shah N., Myllyvirta L., Yu A., Nace T. (2018) Boom and Bust 2018. Tracking the Global Coal Plant Pipeline // End Coal, March 2018 // https://endcoal.org/wp-content/uploads/2018/03/BoomAndBust_2018_r4.pdf, дата обращения 12.12.2019.

DOI: 10.23932/2542-0240-2019-12-6-9

\title{
The Role of Electric Power Sector in China's Global Economic Expansion
}

\author{
Raisa A. EPIKHINA \\ Junior Research Fellow \\ Lomonosov Moscow State University, 119991, 1/46, Leninskie Gory, Moscow, Russian \\ Federation \\ E-mail: repikhina@econ.msu.ru \\ ORCID: 0000-0002-9787-2395
}

\section{CITATION: Epikhina R.A. (2019) The Role of Electric Power Sector in China's Global Economic Expansion. Outlines of Global Transformations: Politics, Economics, Law, vol. 12, no 6, pp. 188-202 (in Russian). DOI: 10.23932/2542-0240-2019-12-6-9}

\section{Received: 07.10.2019.}

\begin{abstract}
The article discusses some of the major characteristics and trends of China's economic expansion in the global power industry. It argues that by investing in electricity infrastructure China creates prerequisites for long-term dominance in one of the key sectors in a number of countries and regions. Deals in the power sector are mainly implemented by state-owned companies and facilitated by state-owned financial institutions. In terms of structure and geography, foreign investment in the electricity sector is dominated by traditional types of generation in developing countries. However, China has been diversifying into renewables, nuclear power and grids and entering markets of the developed countries. The creation of a special international organization (GEIDCO) should facilitate its expansion in the electricity sector abroad. It is worth noting that foreign economic expansion plays an important role in supporting China's slowing economy
\end{abstract}

amid the transformation of its growth model. It allows China to adopt advanced technologies and best management practices in developed countries while forming alternative value chains, as well as promoting its own equipment and standards (especially in ultra-high voltage power transmission) in the developing countries. However, given the impact of the trade war, increasing securitization of the Chinese foreign investments, Chinese authorities' control over capital outflows and the rising environmental concerns in developing countries, further expansion of the Chinese capital in the global electricity industry is likely to be held back, while competition from non-Chinese electricity companies is likely to grow.

KEY WORDS: China, investment, innovation, multinational companies, international economic relations, electric power sector, coal, power grids 
References

Cabré M.M., Gallagher K.P., Li Z. (2018) Renewable Energy: The Trillion Dollar Opportunity for Chinese Overseas Investment. China \& World Economy, vol. 26, no 6, pp. 27-49. DOI: 10.1111/cwe.12260

Dan X., Qiu Z., Lin J. (2018) Overseas Investment Opportunities in the Power Sector. China's Electricity Industry Transformation Series. PwC, January 15, 2018. Available at: https://www.strategyand.pwc. $\mathrm{com} / \mathrm{media} /$ file/PU-series-Overseas-investment-opportunities-in-the-power-sector CN.pdf, accessed 12.12.2019 (in Chinese).

Gallagher K.P., Kamal R., Jin J., Chen Y., Ma X. (2018) Energizing Development Finance? The Benefits and Risks of China's Development Finance in the Global Energy Sector. Energy Policy, vol. 122, pp. 313321. DOI: 10.1016/j.enpol.2018.06.009

Gelbras V.G. (2003) China: Revival of the National Idea. Politeya, no 2, pp. 80-90 (in Russian). DOI: 10.30570/2078-5089-2003-29-2-80-90

Gemueva K.A. (2018) Chinese Infrastructure Projects in Sub-Saharan Africa: Credit Financing. Outlines of Global Transformations: Politics, Economics, Law, vol. 11, no 5, pp. 55-73 (in Russian). DOI: 10.23932/2542-0240-2018-11-5-55-73

Ignatev S., Lukonin S. (2018) China's Investment Relations with African Countries. World Economy and International Relations, vol. 62, no 10, pp. 5-12 (in Russian). DOI: 10.20542/0131-2227-2018-62-10-5-12

Kashin V., Korolev A. (2018) China's Foreign Aid to Central Asia States. World Economy and International Relations, vol. 62, no 3, pp. 78-85 (in Russian). DOI: 10.20542/0131-2227-2018-62-3-78-85

Kong B., Galagher K.P. (2016) The Globalization of Chinese Energy Companies: The Role of State Finance. Boston University, June 2016. Available at: https://www.bu.edu/ pardeeschool/files/2016/06/Globalization. Final_.pdf, accessed 12.12.2019.
Kong B., Gallagher K.P. (2017) Globalizing Chinese Energy Finance: The Role of Policy Banks. Journal of Contemporary China, vol. 26, no 108, pp. 834-851. DOI: $10.1080 / 10670564.2017 .1337307$

Luchko M. (2017) Chinese Transnational Corporations at the World Investment Field. World Economy and International Relations, vol. 61, no 9, pp. 45-53 (in Russian). DOI: 10.20542/0131-2227-2017-61-9-45-53

Mazzucchi N. (2018) China and European Electricity Networks: Strategy and Issues. Fondation pour la Recherche Stratégique. Note №17/2018, September 12, 2018. Available at: https://www.frstrategie.org/sites/default/files/documents/publications/notes/2018/201817.pdf, accessed 12.12.2019.

Nicholas S. (2018) China Is Investing Heavily in European Wind. Asian Superpower's Renewable Energy Ambitions Go beyond Its Belt and Road Footprint. Institute for Energy Economics and Financial Analysis, August 2018. Available at: http://ieefa.org/wp-content/uploads/2018/08/China_Research_Brief_ August-2018.pdf, accessed 12.12.2019.

Ren P., Liu C., Zhang L. (2017) China's Involvement in Coal-fired Power Projects along the Belt and Road. Global Environmental Institute, May 2017. Available at: http://www.geichina.org/_upload/file/report/China\%27s_Involvement_in_Coalfired_Power_Projects_OBOR_EN.pdf, accessed 12.12.2019.

Shearer C., Mathew-Shah N., Myllyvirta L., Yu A., Nace T. (2018) Boom and Bust 2018. Tracking the Global Coal Plant Pipeline. End Coal, March 2018. Available at: https://endcoal.org/wp-content/ uploads/2018/03/BoomAndBust_2018_ r4.pdf, accessed 12.12.2019.

Vasilenko A.S., Chernyadyev D.N., Vlasov S.A. (2018) Structural Transformation of China's Economy: Success or Failure? Voprosy Ekonomiki, no 7, pp. 65-81 (in Russian). DOI: 10.32609/0042-8736-2018-7-65-81 